\title{
Imidazolium ion tethered TsDPENs as efficient ligands for Iridium catalyzed asymmetric transfer hydrogenation of $\alpha$-keto phosphonates in water
}

Mengxia Sun, ${ }^{\mathrm{a}}$ Joann Campbell, ${ }^{\mathrm{a}}$ Guowei Kang, ${ }^{a}$ Huigang Wang, ${ }^{\mathrm{b}}$ and Bukuo $\mathrm{Ni}^{\mathrm{a}, *}$

${ }^{a}$ Department of Chemistry, Texas A\&M University-Commerce, Commerce, TX 75429-3011, USA

${ }^{\mathrm{b}}$ Department of Chemistry, Zhejiang Sci-Tech University, 310018, China

*E-mail: bukuo.ni@tamuc.edu

\begin{abstract}
For the first time, an efficient method has been developed by the use of imidazolium ion tethered TsDPENs as efficient ligands for iridium-catalyzed asymmetric transfer hydrogenation (ATH) of $\alpha$-ketophosphonates in water. The reaction provided the desired product $\alpha$-hydroxyphosphonates in moderate to good yields (44-78\%) and good to excellent enantioselectivities (up to $>99 \%$ ee) under mild reaction conditions without adding any surfactants. The enantiomeric excess was determined by ${ }^{13} \mathrm{P}$ NMR by using (-)-cinchonidine as chiral solvating agent, which is a much more convenient method than chiral HPLC.
\end{abstract}

Keywords: Asymmetric transfer hydrogenation, iridium, $\alpha$-ketophosphonates, water 


\section{Introduction}

Optically active $\alpha$-hydroxy phosphonates are an important class of biologically active compounds, which can be further used as versatile chiral building blocks for a variety of key structural elements in pharmaceuticals and natural products [1]. Thus, it is not surprising that the development of efficient asymmetric catalytic methods for the synthesis of these invaluable chiral $\alpha$-hydroxy phosphonates have received much attention in recent years [2-3]. Among the numerous methods developed, the asymmetric hydrophosphonylation of carbonyl compounds with dialkylphosphite is well established [4]. Another efficient and convenient route to chiral $\alpha$-hydroxy phosphonates is the asymmetric reduction of easily available $\alpha$-keto phosphonates, such as asymmetric reduction with borane using chiral auxiliaries [5] or with catecholborane in the presence of chiral oxazaborolydine catalysts [6] and the asymmetric hydrogenation [7]; however, most of these methods require relatively high catalyst loadings and/or result in low enantioselectivity. Therefore, it is still highly desirable to develop an efficient catalytic system for the synthesis of chiral $\alpha$-hydroxy phosphonates with high enantioselectivity.

Recently, asymmetric transfer hydrogenation (ATH) of ketones has proven to be one of the most versatile and powerful approaches for the synthesis of chiral hydroxyl compounds due to its safety and easy operation [8]. Over the past two decades, the $\mathrm{ATH}$ of ketones with catalysts of transition metals $\mathrm{Ru}, \mathrm{Rh}$, and Ir complexes of chiral ligand TsDPEN ( $p$-toluenesulfonyldiphenylethylenediamine) and their modifications has been studied extensively and achieved great success [8]. Surprisingly, little 
progress has been achieved for ATH of $\alpha$-keto phosphonates [9]. This is probably due to the lability of $\alpha$-keto phosphonates in the presence of some transition metal complexes [10]. So far, only one example has been reported by Johnson and co-worker, in which the Ru-catalyzed ATH of $\alpha$-keto phosphonates was described by the use of $\mathrm{HCO}_{2} \mathrm{H} / \mathrm{Et}_{3} \mathrm{~N}$ as a hydride source and DMSO as a solvent, giving the desired products $\alpha$-hydroxy phosphonates with high enantioselectivity [9]. Recently, ATH performed in water has received growing interest due to its potential benefits in terms of being economic, environmentally benign and hazardless in handling compared to organic solvents. Unfortunately, to the best of our knowledge, no ATH of $\alpha$-keto phosphonates performed in water solvent has been reported. One aspect of our research is aimed at the development of effective and water-compatible catalysts for asymmetric chemical transformations in aqueous media [11]. We recently reported imidazolium ion tethered TsDPENs as efficient water-compatible ligands for rhodium catalyzed ATH of aromatic ketones in water with high enantioselectivity [12]. This result inspired us to extend the method to $\alpha$-keto phosphonates in pure water. Herein, we wish to report our preliminary results.

\section{Results and discussion}

The imidazolium ion tethered TsDPENs L2-L3 (Figure 1) were synthesized according to the procedures that we reported previously by our research group [12]. 


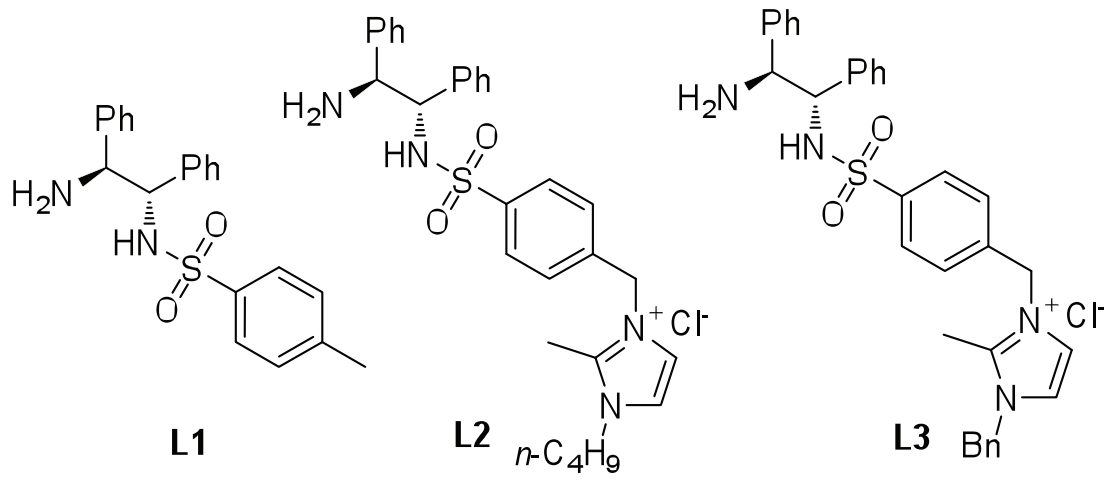

Figure 1. TsDPEN and imidazolium ion tethered TsDPENs

To examine the performance of ligands $\mathbf{L 2}$ and $\mathbf{L 3}$, the ATH of diethyl benzoylphosphonate 1a was selected as a model reaction for screening the metal catalysts and the amount of hydride donor $\mathrm{HCO}_{2} \mathrm{Na}$ and the results are summarized in Table 1. As shown in Table 1, when the reaction was performed in water with $1 \mathrm{~mol} \%$ of $\left[\mathrm{IrCl}_{2} \mathrm{Cp}^{*}\right]_{2}$ as catalyst, $2 \mathrm{~mol} \%$ of original TsDPEN $\mathbf{L 1}$ as ligand, and 5 equiv. of $\mathrm{HCO}_{2} \mathrm{Na}$ as hydride donor, the reaction proceeded smoothly at room temperature for $24 \mathrm{~h}$ affording the desired product diethyl (hydroxyl(phenyl)methylphosphonate 2a in $58 \%$ yield with good enantioselectivity $(71 \%$ ee) (entry 1$)$; however, the metal salt $\left[\mathrm{RhCl}_{2} \mathrm{Cp}^{*}\right]_{2}$ with the ligand $\mathbf{L} \mathbf{1}$ was used as catalyst, the reaction suffered from reduced enantioselectivity with only $7 \%$ ee and lower reactivity (entry 2 ). When $\left[\mathrm{RuCl}_{2}(p \text {-cymene })\right]_{2}$ with $\mathbf{L 1}$ was used as catalyst, the reaction also resulted in lower reactivity and enantioselectivity in comparison to the catalyst $\left[\mathrm{IrCl}_{2} \mathrm{Cp}^{*}\right]_{2}$ (entry 3). These results demonstrate that the metal salt $\left[\mathrm{IrCl}_{2} \mathrm{Cp}^{*}\right]_{2}$ showed the best performance in terms of chemical yield and enantioselectivity. In order to further optimize the reaction conditions, the imidazolium tether ligands $\mathbf{L 2}$-L3 were examined (entries 4-5). We found that both $\mathbf{L} 2$ and $\mathbf{L 3}$ showed comparable reactivity; however, the ligand L2 gave slightly higher enantioselectivity with $77 \%$ ee. These results indicate 
that ligand $\mathbf{L 2}$ with the introduction of imidazolium ion into TsDPEN, greatly increased the reactivity and slightly enhanced the enantioselectivity in comparison with the original ligand TsDPEN L1. In the next set of experiments, temperature and reaction time effects were studied. When the reaction was carried out at $4^{\circ} \mathrm{C}$, the same enantioselectivity and chemical yield were obtained (entry 6). Comparable chemical yields were observed, although the reaction time was prolonged to 8 and 16 hours, respectively (entries 7-8). The influence of hydride donor $\mathrm{HCO}_{2} \mathrm{Na}$ loading was also investigated. Interestingly, when the amount of $\mathrm{HCO}_{2} \mathrm{Na}$ was reduced to 2.0 equiv., the enantioselectivity increased to $84 \%$ ee (entry 9). Increasing the amount of hydride donor $\mathrm{HCO}_{2} \mathrm{Na}$ to 8 equiv. was also not beneficial to the selectivity and chemical yield (entry 10). The absolute stereochemistry of product 2a was determined to be the $(R)$ configuration $\left([\alpha]_{\mathrm{D}}^{25}=+23.7\left(\mathrm{c}=0.9, \mathrm{CHCl}_{3}\right)\right.$ at $84 \%$ ee $)$, in comparison with the optical rotation data that reported by literature $[7 b]$.

Table 1. Optimization of reaction conditions for the ATH of diethyl benzoylphosphonate $\mathbf{1} \mathbf{a}^{\mathrm{a}}$

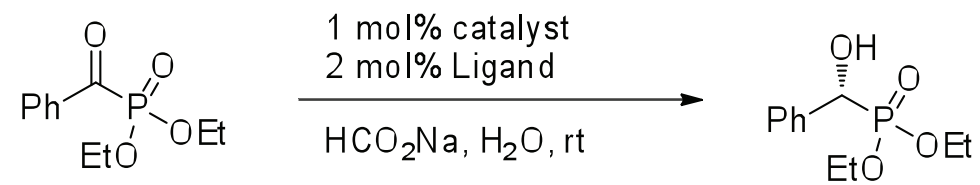

$1 \mathbf{a}$

2a

\begin{tabular}{lllllcc}
\hline entry & catalyst & ligand & $\begin{array}{l}\mathrm{HCO}_{2} \mathrm{Na} \\
\text { (equiv.) }\end{array}$ & T (h) & yield $(\%)^{\mathrm{b}}$ & ee (\%) \\
\hline 1 & {$\left[\mathrm{IrCl}_{2} \mathrm{Cp}^{*}\right]_{2}$} & $\mathbf{L 1}$ & 5 & 24 & 58 & 71 \\
2 & {$\left[\mathrm{RhCl}_{2} \mathrm{Cp}^{*}\right]_{2}$} & $\mathbf{L 1}$ & 5 & 24 & 43 & 7 \\
3 & {$\left[\mathrm{RuCl}_{2}(\mathrm{p}-\right.$} & $\mathbf{L 1}$ & 5 & 24 & 39 & 57 \\
& ${\text { cymene })]_{2}}$ & & & & & \\
4 & {$\left[\mathrm{IrCl}_{2} \mathrm{Cp}\right]_{2}$} & $\mathbf{L 2}$ & 5 & 4 & 70 & 77 \\
5 & {$\left[\mathrm{IrCl}_{2} \mathrm{Cp}^{*}\right]_{2}$} & $\mathbf{L 3}$ & 5 & 4 & 72 & 71 \\
$6^{\mathrm{d}}$ & {$\left[\mathrm{IrCl}_{2} \mathrm{Cp}^{*}\right]_{2}$} & $\mathbf{L 2}$ & 5 & 4 & 70 & 77
\end{tabular}




\begin{tabular}{lllllll}
7 & {$\left[\mathrm{IrCl}_{2} \mathrm{Cp}^{*}\right]_{2}$} & $\mathbf{L 2}$ & 5 & 8 & 69 & 78 \\
8 & {$\left[\mathrm{IrCl}_{2} \mathrm{Cp}^{*}\right]_{2}$} & $\mathbf{L 2}$ & 5 & 16 & 67 & 78 \\
$\mathbf{9}$ & {$\left[\mathrm{IrCl}_{2} \mathbf{C p}\right]_{2}$} & $\mathbf{L 2}$ & $\mathbf{2}$ & $\mathbf{4}$ & $\mathbf{7 0}$ & $\mathbf{8 4}$ \\
10 & {$\left[\mathrm{IrCl}_{2} \mathrm{Cp}^{*}\right]_{2}$} & $\mathbf{L 2}$ & 8 & 4 & 69 & 76 \\
\hline
\end{tabular}

${ }^{\mathrm{a}}$ ATH was carried out with $0.5 \mathrm{mmol}$ of substrate and $1.0 \mathrm{~mol} \%$ of $\left[\mathrm{IrCl}_{2} \mathrm{Cp}^{*}\right]_{2}$ and $2.0 \mathrm{~mol} \%$ of ligands in $1 \mathrm{~mL}$ water.

${ }^{\mathrm{b}}$ isolated yields.

${ }^{\mathrm{c}}$ The enantiomeric excesses were determined by ${ }^{13} \mathrm{P}$ NMR by using (-)-cinchonicdine as chiral solvating agent [13].

${ }^{\mathrm{d}}$ The reaction was performed at $4^{\circ} \mathrm{C}$.

On the basis of the results summarized in Table 1, the reaction conditions of entry 9

(Table 1) were chosen as standard reaction conditions to study the substrate scope of $\alpha$-keto phosphonates for the ATH and the results are summarized in Table 2. From these results, it is obvious that the ester functional group had an important influence on the enantioselectivity. When the series of dialkyl benzoylphosphonates, dimethyl ester $\mathbf{2 b}$, diethyl ester $\mathbf{2 a}$, and diisopropyl ester $\mathbf{2 c}$, were examined under standard reaction conditions, the results indicated that the introduction of a more bulkier diisopropyl ester $\mathbf{2 c}$ resulted in an appreciably higher reactivity and selectivity than diethyl ester $\mathbf{1 b}$ and dimethyl ester 1a (entry 3 vs entries 1-2). Next, a variety of diisopropyl $\alpha$-keto phosphonates $\mathbf{2 d - I}$ were subjected to ATH reactions and afforded the corresponding diisopropyl $\alpha$-hydroxy phosphonates 3d-l in moderate to good yields with high to excellent enantioselectivities (entries 4-12). The nature of the substitutes on aromatic ring slightly influenced the reactivity and enantioselectivity (entries 4-10). For diisopropyl benzoylphosphonates 1d-g bearing electron-donating and electron-withdrawing groups at 4-substituted positions gave the corresponding products $2 \mathbf{d}-\mathrm{g}$ in high ee values in the range of $88-94 \%$ with various ranges of chemical yields from $56 \%$ to $76 \%$ (entries $4-8$ ). The diisopropyl benzoylphosphonates 
with bromo substitution at the para (1h), ortho (1i), and meta (1j) positions were also investigated and found that both para and ortho bromo diisopropyl benzoylphosphonates $\mathbf{1 h}$-i gave comparable levels of reactivity and selectivity (entries 8-9); however, the meta bromo diisopropyl benzoylphosphonate $\mathbf{1 j}$ resulted in relative low enantioselectivity (entry 10). In addition to the aromatic substrates, the aliphatic substituted group substrate diisopropyl phenylacetylphosphonate $\mathbf{1 k}$ and diisopropyl phenylpropanoylphosphonate $\mathbf{1 l}$ were also examined under the optimized reaction conditions and provided the corresponding products $\mathbf{2 k - 1}$ in excellent ee values of $>99 \%$ with moderate yields (entries 11-12).

Table 2. ATH of $\alpha$-keto phosphonates ${ }^{\mathrm{a}}$

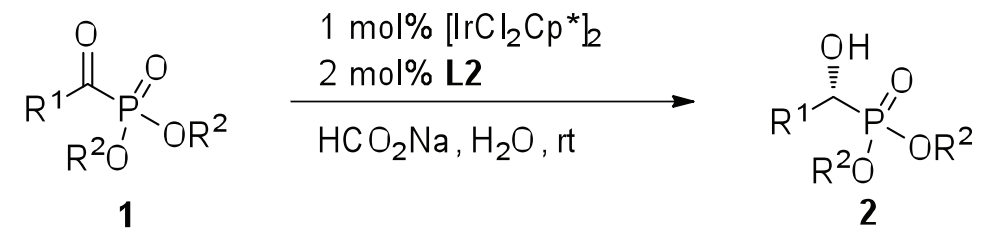

\begin{tabular}{cccccccc}
\hline entry & substrate & $\mathrm{R}^{1}$ & $\mathrm{R}^{2}$ & $\mathrm{~T}(\mathrm{~h})$ & product & ${\text { yield }(\%)^{\mathrm{b}}}^{\text {ee }(\%)^{\mathrm{c}}}$ \\
\hline 1 & $\mathbf{1 b}$ & $\mathrm{Ph}$ & $\mathrm{Me}$ & 6 & $\mathbf{2 b}$ & 44 & 69 \\
2 & $\mathbf{1 a}$ & $\mathrm{Ph}$ & $\mathrm{Et}$ & 4 & $\mathbf{2 a}$ & 70 & 84 \\
3 & $\mathbf{1 c}$ & $\mathrm{Ph}$ & $i-\mathrm{Pr}$ & 4 & $\mathbf{2 c}$ & 76 & 87 \\
4 & $\mathbf{1 d}$ & $4-\mathrm{MeC}_{6} \mathrm{H}_{4}$ & $i-\mathrm{Pr}$ & 6 & $\mathbf{2 d}$ & 67 & 94 \\
5 & $\mathbf{1 e}$ & $4-\mathrm{MeOC}_{6} \mathrm{H}_{4}$ & $i$-Pr & 6 & $\mathbf{2 e}$ & 58 & 88 \\
6 & $\mathbf{1 f}$ & $4-\mathrm{FC}_{6} \mathrm{H}_{4}$ & $i-\mathrm{Pr}$ & 4 & $\mathbf{2 f}$ & 56 & 89 \\
7 & $\mathbf{1 g}$ & $4-\mathrm{ClC}_{6} \mathrm{H}_{4}$ & $i-\mathrm{Pr}$ & 6 & $\mathbf{2 g}$ & 62 & 92 \\
8 & $\mathbf{1 h}$ & $4-\mathrm{BrC}_{6} \mathrm{H}_{4}$ & $i-\mathrm{Pr}$ & 4 & $\mathbf{2 h}$ & 76 & 93 \\
9 & $\mathbf{1 i}$ & $2-\mathrm{BrC}_{6} \mathrm{H}_{4}$ & $i-\mathrm{Pr}$ & 4 & $\mathbf{2 i}$ & 78 & 91 \\
10 & $\mathbf{1 j}$ & $3-\mathrm{BrC}_{6} \mathrm{H}_{4}$ & $i-\mathrm{Pr}$ & 4 & $\mathbf{2 j}$ & 75 & 84 \\
11 & $\mathbf{1 k}$ & $\mathrm{PhCH}_{2}$ & $i-\mathrm{Pr}$ & 6 & $\mathbf{2 k}$ & 58 & $>99$ \\
12 & $\mathbf{1 1}$ & $\mathrm{PhCH}_{2} \mathrm{CH}_{2}$ & $i-\mathrm{Pr}$ & 8 & $\mathbf{2 l}$ & 56 & $>99$ \\
\hline
\end{tabular}

${ }^{\mathrm{a}}$ ATH was carried out with $0.5 \mathrm{mmol}$ of substrate, $1.0 \mathrm{~mol} \%$ of $\left[\mathrm{IrCl}_{2} \mathrm{Cp}^{*}\right]_{2}, 2.0$ $\mathrm{mol} \%$ of ligand $\mathbf{L 2}$, and $2.0 \mathrm{~mol} \%$ of $\mathrm{HCO}_{2} \mathrm{Na}$ in $1 \mathrm{~mL}$ water.

$\mathrm{b}$ isolated yields.

${ }^{\mathrm{c}}$ The enantiomeric excesses were determined by ${ }^{13} \mathrm{P}$ NMR by using (-)-cinchonicdine as chiral solvating agent [13]. 


\section{Conclusion}

In conclusion, we have developed a water compatible imidazolium ion tethered TsDPEN ligands for Iridium-catalyzed ATH of a broad range of $\alpha$-keto phosphonates in water, providing the desired products $\mathbf{2 a - 1}$ in moderate to good chemical yields with good to excellent enantioselectivities (up to $>99 \%$ ee). The reaction can be conducted under mild conditions with low catalyst loading, and the hydride donor loading can also be lowered to 2.0 equiv. of $\mathrm{HCO}_{2} \mathrm{Na}$ without affecting the reactivity and enantioselectivity. Further investigation is underway to expand the scope and application of this efficient ATH process.

\section{Experimental}

4.1 General experimental procedure for asymmetric transfer hydrogenation of $\alpha$-keto phosphonates in water

The solution of $\left[\mathrm{IrCl}_{2} \mathrm{Cp}^{*}\right]_{2}(1 \mathrm{~mol} \%)$ and chiral ligand $\mathbf{L 2}(2 \mathrm{~mol} \%)$ in water $(1 \mathrm{~mL})$ was stirred at room temperature for 30 min. Subsequently, dialkyl benzoylphosphonate $1(0.4 \mathrm{mmol})$ and sodium formate $(0.8 \mathrm{mmol})$ was added to the reaction mixture. After reaction mixture was stirred for the desired time, dichloromethane was added to extract the product. The organic phase dried over $\mathrm{Na}_{2} \mathrm{SO}_{4}$. Removal of the organic solvent gave the crude product, which was purified by flash chromatography column on silica gel to afford the product 2 .

\section{Acknowledgment}

This research was supported National Science Foundation (CHE-1213287), McNair Scholars Program (P217A090190-12), and the Robert A. Welch Foundation (T-0014). 
The authors are also grateful for the collaborative support from the National Natural Science Foundation of China (21271155 and 21473161). We gratefully acknowledge Prof. Allan D. Headley for his fruitful discussion for this research work.

\section{References:}

[1] (a) R. L. Hilderbrand, The Role of Phosphonates in Living Systems; CRC Press: Boca Raton, 1983;

(b) J. Stawinski, A. Kraszewski, Acc. Chem. Res. 35 (2002) 952;

(c) P. Savignac, B. Iorga, Morden Phosphonate Chemistry; CRC Press: Boca Raton, 2003.

[2] For some reviews in synthesis of chiral $\alpha$-hydroxy phosphonates, see (a) D. F. Wiemer, Tetrahedron 53 (1997) 16609;

(b) H. Gröger, B. Hammer, Chem. Eur. J. 6 (2000) 943;

(c) O. I. Kolodiazhnyi, Tetrahedron: Asymmetry 16 (2005) 3295;

(d) P. Merino, E. Marqués-López, R. P. Herrera, Adv. Synth. Catal. 350 (2008) 1195.

[3] (a) B. J. Rowe, C. Spilling, Tetrahedron: Asymmetry 12 (2001) 1701;

(b) D. Skropeta, R. Schmidt, Tetrahedron: Asymmetry 14 (2003) 265;

(c) O. Pàmies, J.-E. Bäckvall, J. Org. Chem. 68 (2003) 4815;

(d) V. D. Pawar, S. Bettigeri, S.-S. Weng, J.-Q. Kao, C.-T. Chen, J. Am. Chem. Soc. $128(2006) 6308$.

[4] (a) B. Saito, T. Katsuki, Angew. Chem., Int. Ed. 44 (2005) 4600;

(b) K. Ito, H. Tsutsumi, M. Setoyama, B. Saito, T. Katsuki, Synlett (2007) 1960;

(c) B. Saito, H. Egami, T. Katsuki, J. Am. Chem. Soc. 129 (2007) 1978; 
(d) F. Yang, D. Zhao, J. Lan, P. Xi, L. Yang, S. Xiang, J. You, Angew. Chem., Int. Ed. 47 (2008) 5646;

(e) D. Uraguchi, T. Ito, T. Ooi, J. Am. Chem. Soc. 131 (2009) 3836;

(f) K. Suyama, Y. Sakai, K. Matsumoto, B. Saito, T. Katsuki, Angew. Chem., Int. Ed. 49 (2010) 797;

(g) C. Liu, Y. Zhang, Q. Qian, D. Yuan, Y. Yao, Org. Lett. 16 (2014) 6172;

(h) H. Wynberg, A. A. Smaardijk, Tetrahedron Lett. 24 (1983) 5899;

(i) T. Arai, M. Bougauchi, H. Sasai, M. Shibasaki, J. Org. Chem. 61 (1996) 2926;

(j) X. Zhou, X. Liu, X. Yang, D. Shang, J. Xin, X. Feng, Angew. Chem., Int. Ed. 47 (2008) 392.

[5] E. V. Gryshkun, V. Nesterov, O. I. Kolodyazhnyi, Arkivoc (2012) 100.

[6] (a) C. Meier, W. H. Laux, Tetrahedron: Asymmetry 6 (1995) 1089;

(b) C. Meier, W. H. G. Laux, Tetrahedron 52 (1996) 589.

[7] (a) N. S. Goulioukina, G. N. Bondarenko, A. V. Bogdanov, K. N. Gavrilov, I. P. Beletskaya, Eur. J. Org. Chem. (2009) 510;

(b) Q. Li, C.-J. Hou, Y.-J. Liu, R.-F. Yang, X.-P. Hu, Tetrahedron: Asymmetry 26 (2015) 617.

[8] For selected reviews on ATH of ketones, see: (a) T. Ikariya, A. J. Blacker, Acc. Chem. Res. 40 (2007) 1300;

(b) R. Noyori, S. Hashiguchi, Acc. Chem. Res. 30 (1997) 97;

(c) C. Wang, X. Wu, J. Xiao, Chem. Asian J. 3 (2008) 1750;

(d) X. Wu, C. Wang, J. Xiao, Platinum Met. Rev. 54 (2010) 3; 
(e) X. Wu, J. Xiao, Chem. Commun. (2007) 2449;

(f) M. J. Palmer, M. Wills, Tetrahedron: Asymmetry 10 (1999) 2045;

(g) B. Štefane, F. Požgan, Catal. Rev. 56 (2014) 82.

[9] M. T. Corbett, J. S. Johnson, J. Am. Chem. Soc. 135 (2013) 594.

[10] H. Nakazawa, Y. Matsuoka, I. Nakagawa, K. Miyoshi, Organometallics 11 (1992) 1385.

[11] (a) Z. Zheng, B. L. Perkins, B. Ni, J. Am. Chem. Soc. 132 (2010) 50;

(b) S. K. Ghosh, Z. Zheng, B. Ni, Adv. Synth. Catal. 352 (2010) 2378;

(c) C. Poornima, S. K. Ghosh, G. E. Long, A. D. Headley, B. Ni, Adv. Synth. Catal. 353 (2011) 2909;

(d) Y. Qiao, Q. Chen, S. Lin, B. Ni, A. D. Headley, J. Org. Chem. 78 (2013) 2693;

(e) Q. Chen, Y. Qiao, B. Ni, Synlett. 24 (2013) 839.

[12] G. Kang, S. Lin, A. Shiwakoti, B. Ni, Catal. Commun. 57 (2014) 111.

[13] (a) V. V. Nesterov, O. I. Kolodiazhnyi, Tetrahedron: Asymmetry 17 (2006) 1023 ;

(b) V. V. Nesterov, E. V. Gryshkun, O. I. Kolodiazhnyi, J. Gen. Chem. 75 (2005) 1161. 